\title{
An Empirical Study of Corpus Application in the Teaching of English Writing
}

\author{
Caiqiao Huo ${ }^{1,2}$, Liping Jiao1, Wenjun Wang1 \\ ${ }^{1}$ College of Foreign Language Education and International Business, Baoding University, Baoding, China \\ ${ }^{2}$ School of Chinese language and Literature, Hebei University, Baoding, China \\ Email: goofyhuo@163.com
}

How to cite this paper: Huo, C. Q., Jiao, L. P., \& Wang, W. J. (2021). An Empirical Study of Corpus Application in the Teaching of English Writing. Creative Education, 12, 2464-2470.

https://doi.org/10.4236/ce.2021.1210184

Received: September 16, 2021

Accepted: October 26, 2021

Published: October 29, 2021

Copyright $\odot 2021$ by author(s) and Scientific Research Publishing Inc. This work is licensed under the Creative Commons Attribution International License (CC BY 4.0).

http://creativecommons.org/licenses/by/4.0/

\begin{abstract}
The cultivation of writing ability has always been one of the teaching goals of English majors. It is listed as the five skills of English learning along with listening, speaking, reading and translation. Nowadays, people gradually realize that most Chinese college students' English writing ability is not very satisfactory. One of the problems is that most students are affected by their mother tongue. The Chinese way of thinking hinders the development of their language skills, thus restricting further language learning. English corpus is of great help in terms of vocabulary, grammar usage, monitoring and verification of the correctness of language output. In this paper, the author combines the teaching practice of English writing with the application of English corpus, and conducts research on its effectiveness. Results show that students' language errors in compositions are reduced, their vocabulary becomes richer and more diversified, and students' feedback is very good. Besides, this method can also encourage students to learn independently to improve their writing skills.
\end{abstract}

\section{Keywords}

Corpus, English Writing, Teaching

\section{Introduction}

The cultivation of writing ability has always been one of the goals of English teaching. It is listed as the five skills of English learning along with listening, speaking, reading and translation. Nowadays, it is obvious that most Chinese college students' English writing ability is not quite satisfactory. One of the reasons is that most students are affected by their mother tongue. The Chinese way of thinking hinders the development of their language skills, thus restricting further Language learning. In English writing, most second language learners 
cannot express their ideas correctly. By analyzing the language errors of students' writing, writing teachers have found that most of the mistakes are mainly concerned with word selection, prosody, fixed collocation, etc. (Ye, 2002). The corpus is of great help in terms of vocabulary, grammar use, collocation of language output (Dong \& Chu, 2010). Teng Yanjiang and Liu Shizhu have discussed the possibility of applying corpus to writing teaching (Teng \& Liu, 2006). Although linguists have always emphasized the role of corpus in teaching, the use of corpus in writing teaching is not as common as people have expected. The reason may be that there lacks a corpus which is handful and can be used at any time for teachers and learners. If teachers are used to using corpus, they will be happy to introduce corpus into teaching. English teachers can choose some corpora to assist in teaching on purpose, which is a better way to show the natural use of language to students.

In view of this, the author has made some attempts to apply corpora to the teaching of writing, and found that the Corpus of Contemporary American English, abbreviated as COCA, can help students solve the problem of "how to write" in writing. If teachers can teach students the basic methods of using the corpus, students can discover the mistakes in their compositions by themselves and make corrections, which improves their autonomous learning ability greatly.

\section{Research Background}

Since the 1960s, corpus construction and research have made rapid progress. Researchers and learners have drawn more objective and convincing conclusions by processing language data with computers. At present, some scholars have applied the corpus to the teaching of English writing.

Cai Shaolian finds that learners' writing interests can be aroused by adopting corpus-based teaching method after conducting an empirical research. At the same time, learners' writing ability has been improved, which provides a more effective way than the traditional writing teaching methods (Cai, 2008).

In order to improve students' English writing ability, Liu Qin and He Lei has constructed a corpus-based autonomous learning model for Chinese science and engineering students in English writing and used action research methods to conduct teaching experiments. The results show that integrating corpus technology into autonomous learning and appropriately emphasizing the guiding role of teachers are conducive to students' English writing (Liu \& He, 2017).

To solve the problem that some college English writing teachers paid more attention to the structure and ignored language and content of students' composition, Jin Rong suggests that teachers should introduce corpus to English writing teaching, teach students to use this tool, and then guide students to analyze the stylistic and linguistic characteristics of different genres. The final goal is to improve students' writing abilities (Jin, 2019).

Huang Xiaomei analyzes the role of a small learner corpus which is built by herself. She points out that the small learner corpus built by the teacher can be used in college English writing teaching. Teachers' self-built small learner corpus 
can be used in all aspects of college English writing teaching because of its outstanding advantages such as strong pertinence, clear purpose, and strong operability (Huang, 2019).

The corpus teaching method embodies the concept of data-driven learning (DDL), which was put forward by Johns. The main idea is that learners can discover and summarize the rules of language use by themselves by exploring the word collocation, grammatical rules and pragmatic characteristics (Johns, 1991). As a guide, teachers provide learners with learning resources and guide them to explore and discover continuously in their learning. In this research, the teaching experiment is guided by data-driven theory.

\section{Teaching Experiment Based on COCA}

\subsection{Teaching Platform}

This teaching experiment is based on the application of COCA. The American Contemporary English Corpus, abbreviated as COCA, is currently the largest online English corpus which is free and open. It is composed of five different styles of spoken English, novels, popular magazines, newspapers, and academic articles, expanded at a rate of 20 million words every year to ensure the timeliness of the corpus content. It is considered to be the most suitable English corpus for studying the current development and changes of American English. English learners can use COCA for English learning.

\subsection{Teaching Objects}

This teaching experiment is conducted in the English writing course, which is a compulsory course for the second year English majors of one university in Hebei Province. English writing lasts from September to June each academic year. The objects of this teaching experiment are second year undergraduates from English department taught by the author.

\subsection{Teaching Experiment Process}

This teaching experiment was conducted from March 1, 2021 to March 26, 2021. Thirty students were chosen to participate in the experiment. They are divided into six groups with 5 students in each one. After studying English writing skills in the last semester, students had acquired a certain amount of knowledge about diction, sentences, paragraphs and main styles of writing. Therefore, in the second semester, students were required to do writing practices and make comments as much as they could.

In the first week of the second semester, an argumentative essay was selected as the teaching content, and COCA was used as teaching resources and methods. At the beginning of the teaching experiment in the first week, teacher explained the contents, overall structure and language characteristics of the selected article, and then handed out an article to students, asking students to discuss the main idea of the article in class after reading it, and to write an argumentative essay within 45 minutes. 
In the second week, the teacher first introduced the usage of COCA to the students, and guided the students to use the corpus to modify their own articles, and conducted group evaluation after the modification. In the process of revision and mutual evaluation, students could use COCA and marked them in the article. Each group summarized the problems they had found and presented them in class. At last, they handed the articles to the teacher for final correction.

In the third week, the teacher first summarized and explained the students' overall opinions. The articles were handed out to the students, and the students continued to modify their articles.

In the fourth week, the final draft after the students' corrections will be evaluated by each group and submitted to the teacher after the evaluation.

\section{Teaching Summary}

After students are used to using COCA, they are like being immersed in a real language environment and can learn independently at any time and any place as long as they can get online. Through research, it is found that students can use COCA specifically in the following aspects:

\subsection{Diction}

Because of the influence of Chinese, many Chinese students tend to adopt the way of direct translation when choosing words while writing. For example, there is nothing grammatically wrong with the phrase "study knowledge", but there is no such an expression in English. After search the word "knowledge" in COCA, students can find that the word "study" has never appeared before "knowledge". "Study" and "knowledge" don't match. The most commonly used collocation is "gain knowledge", followed by share knowledge, acquire knowledge, construct knowledge, demonstrate knowledge, etc. In this way, students can check the context and learn the corresponding usage (see Figure 1).

\subsection{Semantic Prosody}

It seems that many words do not have obvious emotional coloring. However, by searching in COCA, some words seem to be neutral, but when they are accompanied by specific vocabulary, they will have some associative meanings, such as praise or dislike. For example, many students often use "cause" when writing, which seems to be a neutral word. Whereas, after searching the word "cause" in COCA, they have found that "cause" is often followed by some derogatory term (see Figure 2). The most common collocation with cause is problems, then cancer, trouble, harm, Damage, etc. "Lead to" has the same translation in Chinese, but after searching it in COCA, it is found that its semantic prosody is relatively neutral. For example, the most common collocation is "changes", followed by violence, success, etc. (see Figure 3).

\subsection{Fixed Collocation}

Some students are not familiar with the fixed collocations in English, and mixes 
vocabulary randomly, especially the mismatch of prepositions. With COCA, students can choose one of the functions of collocation to prove whether that collocation is right or wrong. For example, some students will write a sentence-"he offers an insight about this hot issue" in their compositions. While, searching the word "insight" in COCA, students can find that "insight" and "about" have never appeared together. They can also learn the correct expression "an insight into ..." (see Figure 4).

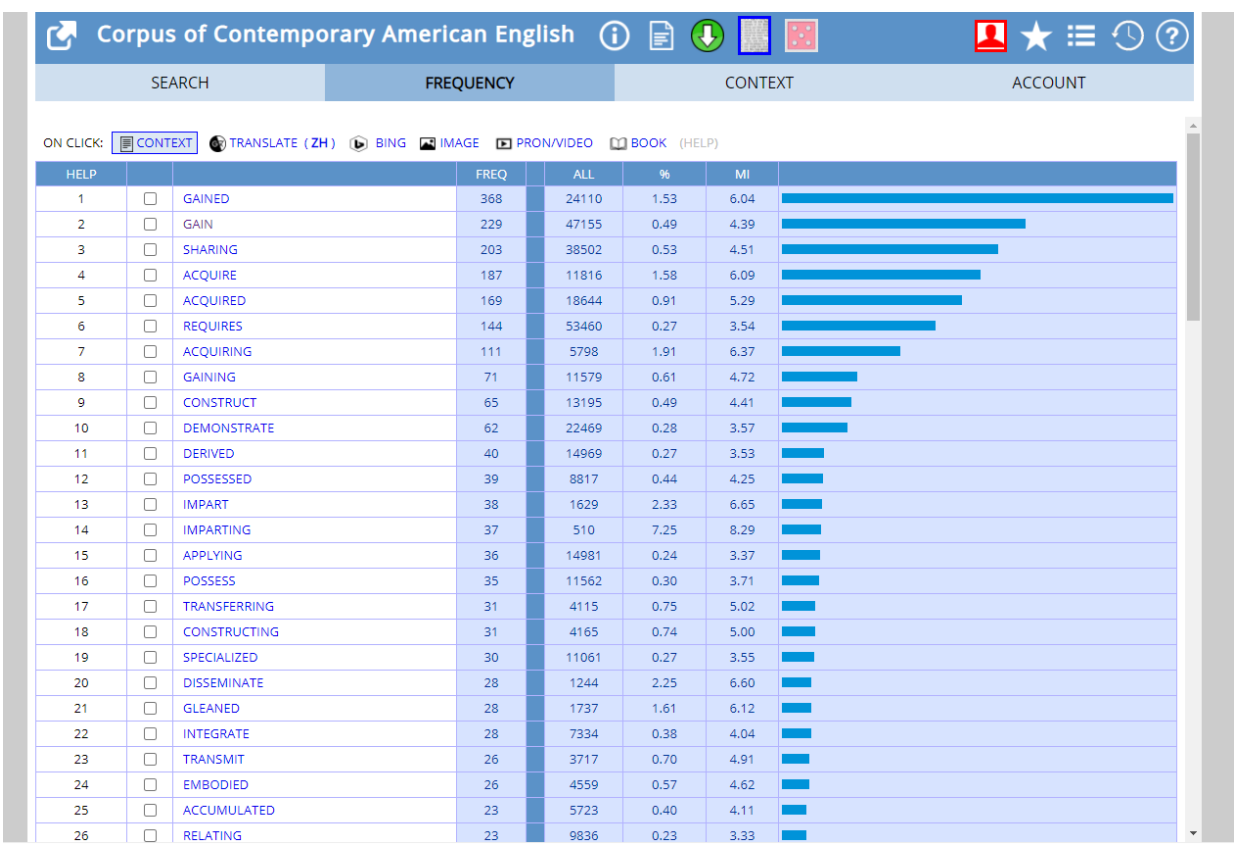

Figure 1. Most Commonly Used Verbs in front of "knowledge".

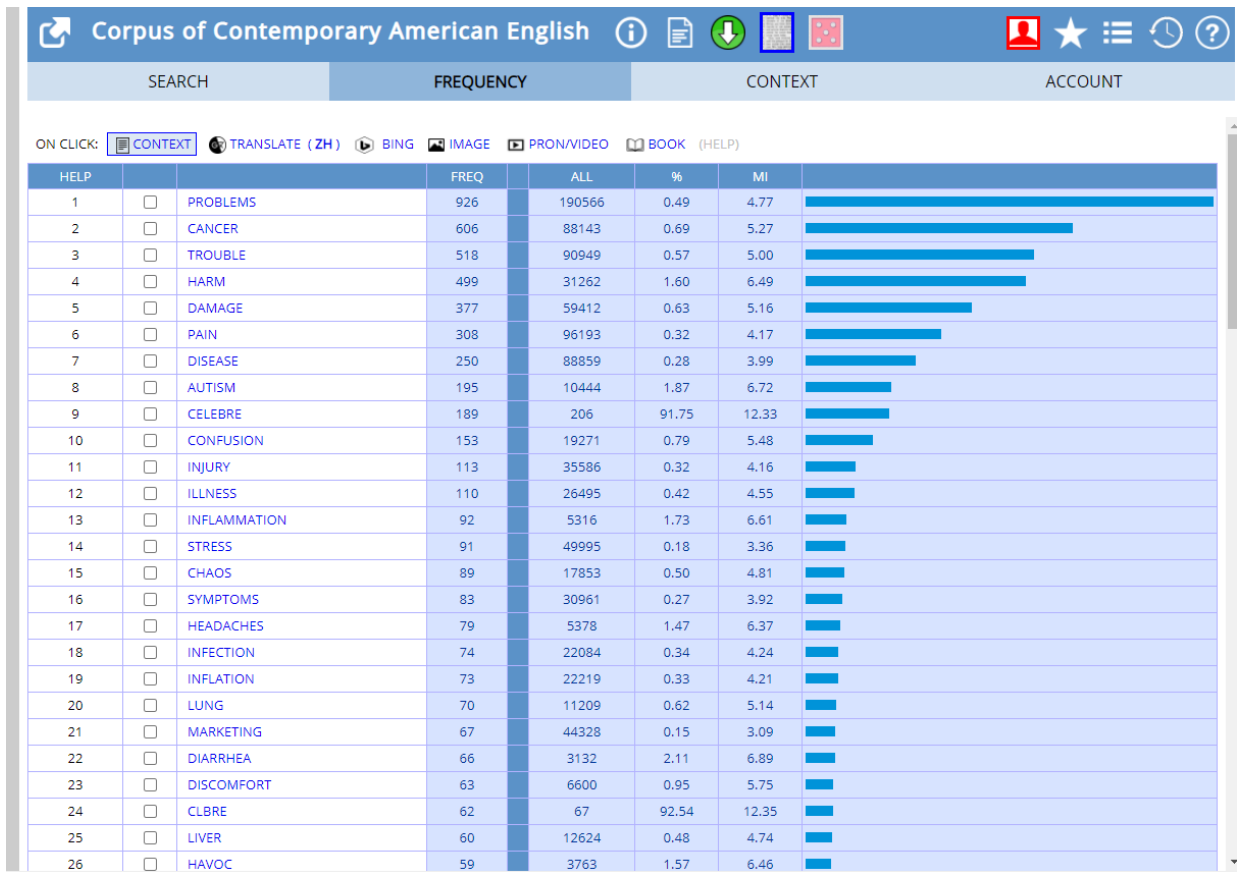

Figure 2. Most Commonly Used words after "cause". 


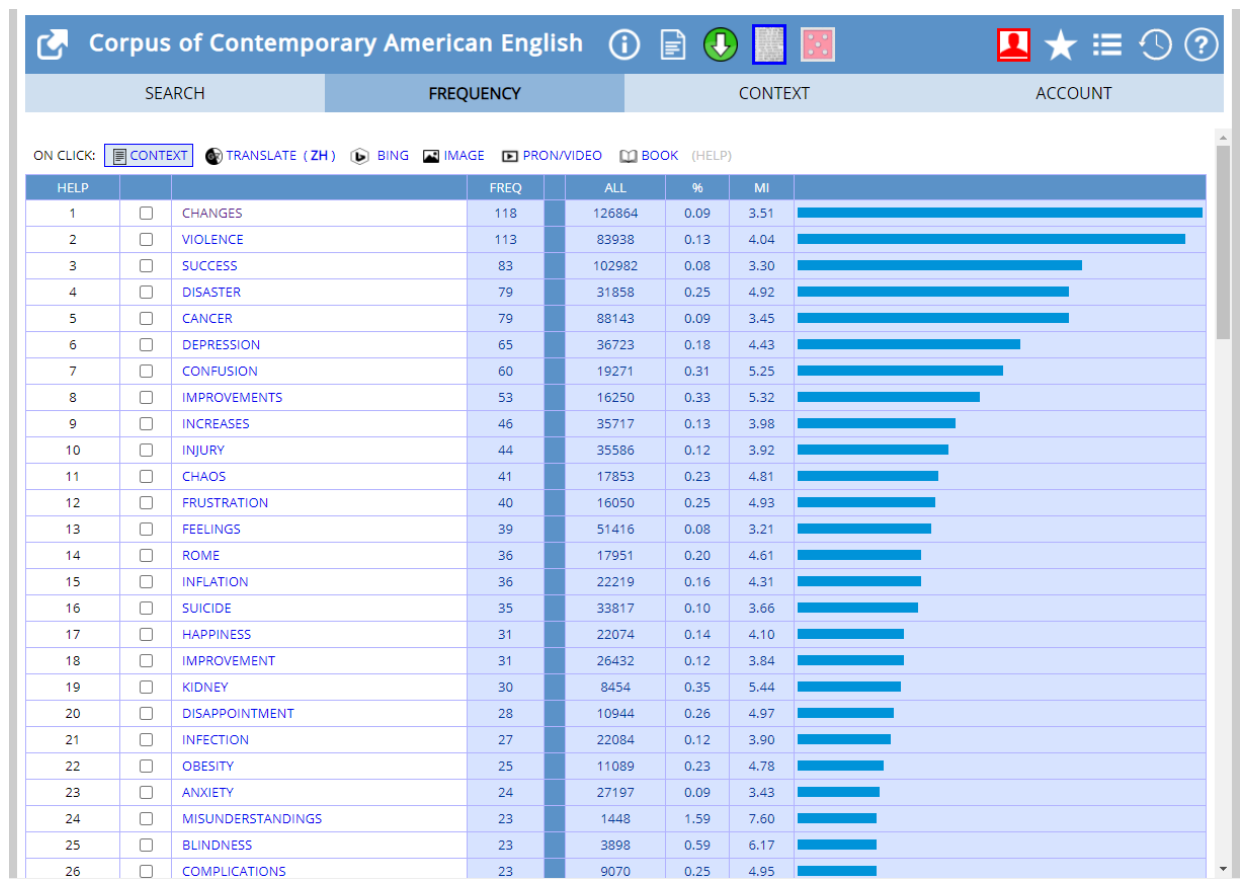

Figure 3. Most Commonly Used words after "lead to".

\begin{tabular}{|c|c|c|c|c|c|c|c|c|}
\hline \multicolumn{3}{|c|}{ SEARCH } & \multicolumn{2}{|c|}{ FREQUENCY } & \multicolumn{3}{|c|}{ CONTEXT } & \multirow[t]{2}{*}{ ACCOUNT } \\
\hline ON CLICK: & CONT & :XT TRANLLATE $(\mathrm{ZH}) \circlearrowright$ BING & ه IMAGE & 曰PRON/NIDEO & Фвоок & & & \\
\hline HELP & & & FREQ & ALL & 96 & MI & & \\
\hline 1 & $\square$ & INTO & 6762 & 1461779 & 0.46 & 7.94 & - & \\
\hline 2 & $\square$ & REGARDING & 59 & 51541 & 0.11 & 5.93 & I & \\
\hline 3 & $\square$ & MEDITATION & 37 & 7499 & 0.49 & 8.03 & 1 & \\
\hline 4 & $\square$ & PORN & 26 & 8308 & 0.31 & 7.38 & I & \\
\hline 5 & 0 & NETWORK & 20 & 80469 & 0.02 & 3.72 & 1 & \\
\hline 6 & $\square$ & GAINED & 19 & 24110 & 0.08 & 5.39 & 1 & \\
\hline 7 & $\square$ & BOWL & 17 & 54619 & 0.03 & 4.05 & 1 & \\
\hline 8 & $\square$ & CONCERNING & 13 & 22600 & 0.06 & 4.93 & I & \\
\hline 9 & $\square$ & MAGAZINE & 13 & 59591 & 0.02 & 3.53 & 1 & \\
\hline 10 & $\square$ & SNAPSHOT & 8 & 3177 & 0.25 & 7.06 & 1 & \\
\hline 11 & $\square$ & COMMUNICATIONS & 7 & 28610 & 0.02 & 3.70 & 1 & \\
\hline 12 & $\square$ & LANDER & 6 & 2025 & 0.30 & 7.30 & 1 & \\
\hline 13 & $\square$ & EDITIONS & 6 & 4218 & 0.14 & 6.24 & 1 & \\
\hline 14 & $\square$ & WHATSOEVER & 5 & 10679 & 0.05 & 4.64 & I & \\
\hline 15 & $\square$ & APPLIES & 5 & 13756 & 0.04 & 4.27 & 1 & \\
\hline 16 & $\square$ & REWARD & 5 & 17076 & 0.03 & 3.96 & 1 & \\
\hline 17 & $\square$ & XTD & 4 & 17 & 23.53 & 13.61 & I & \\
\hline 18 & $\square$ & SCOOP & 4 & 5701 & 0.07 & 5.22 & 1 & \\
\hline 19 & $\square$ & TWO-SEATER & 3 & 278 & 1.08 & 9.16 & 1 & \\
\hline 20 & $\square$ & RIDDLES & 3 & 980 & 0.31 & 7.34 & 1 & \\
\hline 21 & $\square$ & 9.5 & 3 & 1279 & 0.23 & 6.96 & 1 & \\
\hline 22 & $\square$ & AFFORDED & 3 & 3899 & 0.08 & 5.35 & 1 & \\
\hline 23 & $\square$ & NEWSLETTER & 3 & 7943 & 0.04 & 4.33 & 1 & \\
\hline 24 & $\square$ & ENTERPRISES & 3 & 8622 & 0.03 & 4.21 & 1 & \\
\hline 25 & $\square$ & ENABLED & 3 & 9586 & 0.03 & 4.05 & 1 & \\
\hline 26 & $\square$ & GUIDES & 3 & 9792 & 0.03 & 4.02 & I & \\
\hline
\end{tabular}

Figure 4. Most Commonly Used words after "insight".

\section{Conclusion}

After introducing corpus into writing teaching, it is found that students' language errors in composition are reduced. The vocabulary in their compositions has become richer and diversified. Students are satisfied with the aid of COCA, which is considered to be a convenient platform in their English studying. There are some limitations of this teaching research since it is only carried out in four 
weeks. In the future, more research on such kind of online corpus should be conducted.

\section{Acknowledgements}

This paper is under the project of Research on the Application of Corpus in English Writing Feedback (project No. 2020YYJG051) which is sponsored by Hebei Provincial Department of Education and the project of Research on Hebei Tourism Document Translation Based on English-Chinese Diachronic Parallel Corpus (project No. 20210201244) which is sponsored by Social Science Association of Hebei Province. All the project members made their contributions to the paper. I also thank all my friends and classmates who work in different universities, which made the investigation possible.

\section{Conflicts of Interest}

The authors declare no conflicts of interest regarding the publication of this paper.

\section{References}

Cai, S. L. (2008). An Empirical Study of English Writing Teaching Based on Corpus. Foreign Language Education, No. 6, 61-64+68.

Dong, H. X., \& Chu, S. H. (2010). An Empirical Study on the Internet Corpus-Based Teaching Model of English Writing. Technology Enhanced Foreign Language Education, No. 5, 27-32.

Huang, X. M. (2019). On the Auxiliary Function of Teachers' Self-Built Learner's Composition Corpus to the Teaching of College English Writing. Journal of Higher Education, No. 21, 191-193.

Liu, Q., \& He, L. (2017). Construction of a Corpus-Based Self-Regulated Learning Model of English Writing. Technology Enhanced Foreign Language Education, No. 6, 44-49 +77.

Johns, T. F. (1991). Should You Be Persuaded: Two Examples of Data-Driven Learning Materials. English Language Research Journal, No. 4, 1-16.

Jin, R. (2019). Research on the Teaching Model of College English Writing Based on Corpus. Journal of Lanzhou Institute of Education, No. 10, 140-141.

Teng, Y. J., \& Liu, S. Z. (2006). A New Corpus-Based Pattern to the Teaching of English Writing. Technology Enhanced Foreign Language Education, No. 6, 49-54.

Ye, Y. P. (2002). Viewing the Weak Links in Writing Teaching from the Language Errors in Students' Compositions. Foreign Language Education, No. 4, 77-81. 